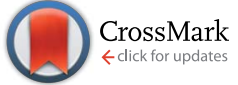

Cite this: RSC Adv., 2016, 6, 41809
Received 3rd March 2016 Accepted 19th April 2016

DOI: $10.1039 / c 6 r a 05732 b$

www.rsc.org/advances

\section{Wettability gradient-induced alignment of peptide nanotubes as templates for biosensing applications $\uparrow$}

\author{
Sawsan Almohammed, ${ }^{\text {ab }}$ Sarah O. Oladapo, ${ }^{\text {K Kate Ryan, }}{ }^{\text {ab }}$ Andrei L. Kholkin, ${ }^{\text {cd }}$ \\ James H. Rice*a and Brian J. Rodriguez ${ }^{* a b}$
}

Self-assembled diphenylalanine (FF) peptide nanotubes (PNTs) have attracted significant attention due to their well-ordered supramolecular structure and wide range of functional capabilities that may enable potential nanobiotechnology applications. However, self-assembled PNTs are generally inhomogeneous at the macroscale, which has limited their potential use. Reproducibly controlling the assembly and alignment of PNTs is therefore critical to enable the widespread use of PNTs, e.g., in sensing applications. In this study, a surface patterning technique based on UV/Ozone exposure through a mask is used to align PNTs. Exposed regions become hydrophilic, leading to directed spreading of the FF solution and alignment of the PNTs that improves as the difference in wettability between adjacent regions increases. Alignment was further found to depend on the concentration- and temperaturedependent diameter of the PNTs formed and the size of the hydrophilic area. Finally, aligned PNTs decorated with silver nanoparticles are used to sense an analyte molecule using surface enhanced Raman spectroscopy.

\section{Introduction}

Self-assembling diphenylalanine (FF) peptide nanotubes (PNTs) are one of the most promising organic building blocks for nanobiotechnology applications owing to their thermal stability, functional properties, and straightforward synthesis. ${ }^{18}$ However, PNTs are generally macroscopically disordered, which limits their potential use, ${ }^{9}$ e.g., as a replacement for lead zirconate titanate in integrated piezoelectric sensors. ${ }^{10}$ Despite extensive efforts to understand and control the self-assembly process, e.g., through evaporation, ${ }^{\mathbf{1 1}}$ temperature,,$^{4,12} 15$ and external fields, ${ }^{1,2,16} 19$ the ability to tailor both the orientation and distribution of these nanostructures remains a challenge. ${ }^{\mathbf{1 , 2 , 9 , 1 1 , 2 0 , 2 1}}$ In order to improve the suitability of PNTbased devices for tissue engineering, molecular sensing, and organic electronics applications, methods to improve the organisation and alignment of PNTs in a predictable manner

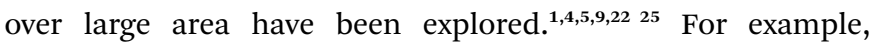

${ }^{a}$ School of Physics, University College Dublin, Belfield, Dublin 4, Ireland. E mail: brian. rodriguez@ucd.ie; james.rice@ucd.ie

${ }^{b}$ Conway Institute of Biomolecular and Biomedical Research, University College Dublin, Belfield, Dublin 4, Ireland

'Department of Physics \& CICECO Aveiro Institute of Materials, 3810193 Aveiro, Portugal

${ }^{d}$ Institute of Natural Sciences, Ural Federal University, 620000 Ekaterinburg, Russia

$\uparrow$ Electronic supplementary information (ESI) available: Representative optical microscopy images of peptide nanotubes. See DOI: 10.1039/c6ra05732b vertically aligned PNTs have been prepared by vapour deposition through mask openings with the aim of developing, e.g., high surface area electrodes that can be used for energy storage applications. ${ }^{9}$ Horizontal alignment has also been reported using magnetic and electric fields. ${ }^{\mathbf{1 , 2 , 1 9}}$ Horizontal alignment by drop casting onto substrates with patterned wettability was achieved by Adler-Abramovich et al. who used electron irradiation and/or UV illumination through regularly spaced $100 \mu \mathrm{m}$ openings to create a substrate with hydrophobic and hydrophilic regions. ${ }^{\mathbf{1 6}}$ Horizontal alignment of PNTs occurred at the edges within hydrophilic regions and the alignment was attributed to differences in wettability. ${ }^{\mathbf{1 6}}$ Despite these efforts, horizontal alignment of PNTs has not advanced significantly beyond this initial demonstration nor has it been explored systematically.

In this study, a surface patterning technique is used to align PNTs. Patterned regions are created by growing a silicon oxide layer on a Si surface via UV/ozone exposure through a Si mask. The degree of alignment is quantified as a function of $\mathrm{FF}$ concentration and mask opening size. Further control over the diameter and density of the PNTs is achieved by heating the FF solution prior to drop casting. While Raman spectroscopy is widely used in the chemical characterisation of materials, including PNTs, ${ }^{26}$ a relatively large amount of analyte is necessary for Raman-based biosensing. Noble metals such as silver (Ag) can enhance the Raman signal, a method referred to as surface enhanced Raman scattering (SERS). ${ }^{30}$ The ability to fill or coat PNTs with metallic nanoparticles (NPs) has been 
previously demonstrated, highlighting the potential use of PNTs in nanoelectronic devices. ${ }^{31}{ }^{33}$ Using aligned PNTs as a template for SERS-active materials may provide a route to improving the reproducibility of the SERS signal by tailoring the density and location of the materials. In the present study, Ag NPs are incorporated into PNTs during self-assembly/alignment and the suitability of the device for sensing an analyte molecule by SERS is explored.

\section{Experimental}

\subsection{Preparation of surface-patterned substrates}

Si substrates (100 orientation, Si Mat) were cleaned of surface contaminants by dipping in acetone for 2 minutes, washing with ethanol and isopropanol, rinsing in deionised water, and drying using nitrogen. ${ }^{6}$ The mask, comprising pieces of a $\mathrm{Si}$ substrate cut using a diamond scribe, was placed in contact with a Si substrate during exposure to UV/ozone (ProCleaner, BioForce) for a specified duration, allowing an oxide layer to grow on the unmasked Si surface (see Fig. 1). The opening size of the mask was varied between $0.9,0.5$, and $0.3 \mathrm{~cm}$ and the width of the central mask region was kept at $0.2 \mathrm{~cm}$ for all experiments. In lieu of cleaning, some samples were etched using hydrofluoric acid (48\%) for 60 seconds to remove the native oxide, washed in deionised water, and blown dry using nitrogen. The etched samples were subsequently stored in ethanol and blown dry using nitrogen prior to UV/ozone exposure. In order to fabricate a wettability gradient, the substrates were selectively exposed to UV/ozone for 1, 2, 3, 5, 10 15, 20 or 30
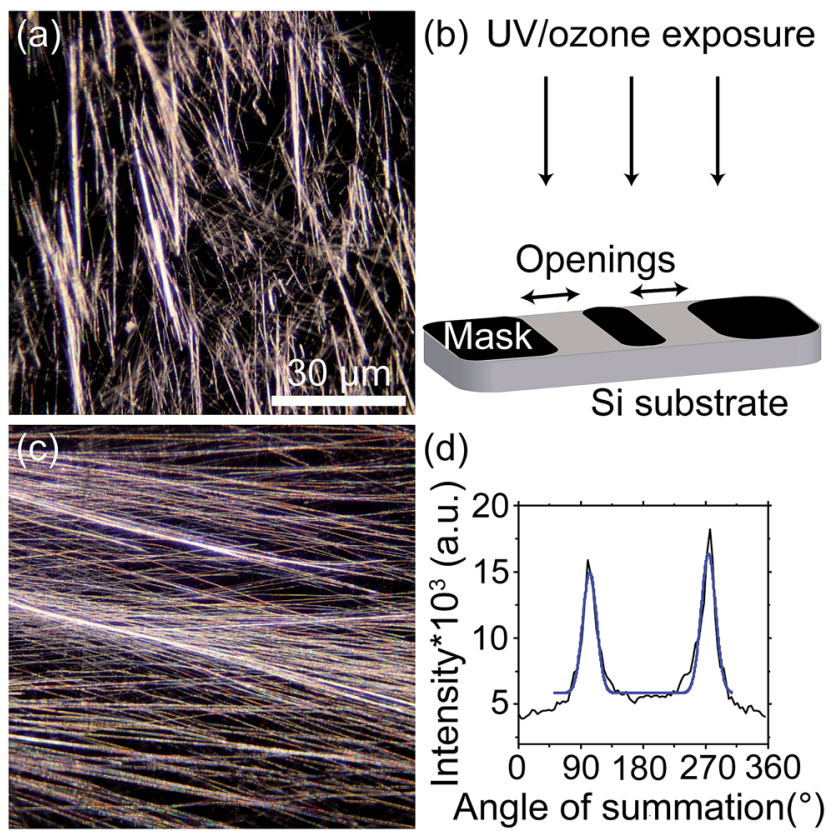

Fig. 1 (a) Optical image of randomly oriented PNTs. (b) Schematic of the mask used to achieve alignment. (c) Optical image of aligned PNTs. (d) Radial summation of the FFT intensity versus angle showing Gaussian fits (blue line) used to determine the FWHM, i.e., the degree of alignment. minutes through the mask openings. Chemicals were purchased from Sigma-Aldrich unless stated otherwise.

\subsection{Preparation of FF stock solution}

Stock solutions of FF were prepared by dissolving the L-diphenylalanine peptide (Bachem, Bubendorf, Switzerland) in 1,1,1,3,3,3-hexafluoro-2-propanol at an initial concentration of $100 \mathrm{mg} \mathrm{ml}^{-1}$ that was further diluted in deionized water to final concentrations of 4,2 , and $0.5 \mathrm{mg} \mathrm{ml}^{-1}$. New solutions were prepared for each alignment experiment.

\subsection{Alignment of PNTs}

Upon removal of the mask, $20 \mu \mathrm{l}$ of FF solution was pipetted onto the centre of the central masked region of the Si substrate (see Fig. 1). In some cases, prior to deposition onto a room temperature substrate, the $2 \mathrm{mg} \mathrm{ml}^{-1} \mathrm{FF}$ solution was heated at $100{ }^{\circ} \mathrm{C}$ for 5 minutes, at which point the solution turned from opaque to clear, a phenomenon previously reported by Huang et al. and attributed to the reversible disassembly of the PNTs. ${ }^{13}$

\subsection{Coating PNTs with Ag NPs}

After heating at $100{ }^{\circ} \mathrm{C}$ for 5 minutes, $90 \mu \mathrm{l} \mathrm{of} 2 \mathrm{mg} \mathrm{ml}^{-1} \mathrm{FF}$ solution was added to a $10 \mu \mathrm{l}$ aqueous solution of $0.02 \mathrm{mg} \mathrm{ml}^{-1}$ $20 \mathrm{~nm}$ diameter Ag NPs (795933, Sigma-Aldrich), which was also heated at $100{ }^{\circ} \mathrm{C}$ for 5 minutes prior to mixing. The combined solution was stirred for 3 minutes and then $20 \mu \mathrm{l}$ was deposited on the room temperature Si substrate that was exposed to UV/ ozone for 20 minutes using a mask with $0.5 \mathrm{~cm}$ openings.

\subsection{Contact angle measurements}

A contact angle (CA) measuring system (DSA10, Krüss) equipped with a camera was used to measure CAs of sessile $10 \mu \mathrm{l}$ droplets of deionised water on UV/ozone exposed and unexposed regions of each Si substrate. The mean and standard deviation of 6 CA measurements is reported.

\subsection{Scanning electron microscopy}

Scanning electron microscopy (SEM) (JSM-7600F, JEOL, operated at $5 \mathrm{kV}$ ) was performed to characterise the morphology of the PNTs. Before imaging, a thin $(\sim 8 \mathrm{~nm})$ layer of gold was sputtered on the substrates (Hummer IV, Anatech USA). The diameters of the PNTs were determined from SEM images. Each value reported is the average diameter of 20 PNTs.

\subsection{Optical microscopy}

Optical micrographs $(10 \times$ objective $)$ were used to quantify the alignment of the PNTs. The radial summation of the fast Fourier transform (FFT) of each image was determined using Image and the radial profile plug-in (National Institutes of Health). The full width at half max (FWHM) of each of the two peaks in the resulting plot of sum versus angle was determined by fitting to a Gaussian function using OriginPro 8.5.1 (OriginLab). For all samples studied, the mean FWHM and standard deviation were calculated typically from 6 images (i.e., 12 peaks), 3 from each mask opening, to account for slight 
variations in the placement of the drop on the centre of the central masked region.

\subsection{Raman spectroscopy}

SERS measurements were performed using a bespoke Raman system comprising an inverted optical microscope (IX71, Olympus) as outlined previously. ${ }^{34,35}$ In brief, a monochromatic laser (HeNe, ThorLabs) with beam splitter and long pass filter (RazorEdge, Semrock), a spectrograph (SP-2300i, Princeton Instruments), and a CCD camera (IXON, Andor). A $50 \times$ objective was used to focus the laser (532 nm wavelength, $5 \mathrm{~mW}$ incident power) and collect the Raman signal with an exposure time of $1 \mathrm{~s} .10 \mu \mathrm{l}$ of $10^{-4} \mathrm{~mol}$ meso-tetra ( $N$-methyl-4-pyridyl) porphine tetrachloride (TMPyP) (T40125, Frontier Scientific) analyte molecule was deposited above the aligned PNTs in the presence and absence of Ag NPs. TMPyP was also deposited above the randomly oriented PNTs for comparison. The average of typically 10 measurements, e.g., within an aligned region, is reported. Calibration of the Raman signal over the spectral window used in this paper was performed using toluene.

\section{Results and discussion}

PNTs deposited on a Si substrate appear macroscopically disordered, having random orientation (Fig. 1(a)). Within the hydrophilic mask openings (Fig. 1(b)) of the UV/ozone patterned substrates, however, alignment of the PNTs is achieved (Fig. 1(c)). The degree of alignment is quantified as the average FWHM of the radial summation of the FFT of the optical micrographs, determined by Gaussian fit (see Fig. 1(d)). The FWHM decreases from $68 \pm 1^{\circ}$ (Fig. 1(a)) to $17 \pm 1^{\circ}$ (Fig. 1(b)) upon alignment of the PNTs.

To understand the alignment mechanism, the wettability gradient between the Si substrate having a native oxide, and the UV/ozone exposed regions has been determined as a function of UV/ozone exposure (Table 1). The difference in CA between unexposed and exposed regions increases with increasing

Table 1 Contact angle measurements for Si substrate and etched Si using different exposure times and resulting FWHM values $\left(2 \mathrm{mg} \mathrm{ml}{ }^{1}\right.$; $0.5 \mathrm{~cm}$ opening). See Fig. S1 for optical images

\begin{tabular}{llrll}
\hline Sample & $\begin{array}{l}\text { UV exposure } \\
(\text { min })\end{array}$ & CA $\left(^{\circ}\right)$ & $\begin{array}{l}\text { CA difference } \\
\left({ }^{\circ}\right)\end{array}$ & \multicolumn{1}{l}{$\begin{array}{l}\text { FWHM } \\
\left({ }^{\circ}\right)\end{array}$} \\
\hline $\mathrm{Si}$ & 0 & $58 \pm 1$ & $\mathrm{NA}$ & $68 \pm 1$ \\
$\mathrm{Si}$ & 1 & $45 \pm 1$ & $13 \pm 1$ & $40 \pm 1$ \\
$\mathrm{Si}$ & 2 & $41 \pm 1$ & $17 \pm 1$ & $35 \pm 1$ \\
$\mathrm{Si}$ & 3 & $33 \pm 2$ & $25 \pm 2$ & $30 \pm 1$ \\
$\mathrm{Si}$ & 5 & $28 \pm 1$ & $30 \pm 1$ & $28 \pm 1$ \\
$\mathrm{Si}$ & 10 & $20 \pm 1$ & $38 \pm 1$ & $24 \pm 1$ \\
$\mathrm{Si}$ & 15 & $9 \pm 1$ & $49 \pm 1$ & $22 \pm 1$ \\
$\mathrm{Si}$ & 20 & $4 \pm 1$ & $54 \pm 1$ & $17 \pm 1$ \\
$\mathrm{Si}$ & 30 & $4 \pm 1$ & $54 \pm 1$ & $18 \pm 1$ \\
Etched & 0 & $74 \pm 1$ & $\mathrm{NA}$ & $71 \pm 2$ \\
$\mathrm{Si}$ & & & & \\
Etched & 20 & $5 \pm 1$ & $69 \pm 1$ & $18 \pm 1$ \\
Si & & & &
\end{tabular}

exposure time until the exposed surface is completely hydrophilic (20 minutes). The degree of alignment improves with increasing exposure time, suggesting the difference in wettability between regions leads to a chemical force, which drives the alignment process. This mechanism is similar to that described by Adler-Abramovich et al. in which the aligned PNTs formed in the hydrophilic regions due to the 'repulsion' of the FF solution from the hydrophobic regions. ${ }^{16}$ Chemical force gradients have also been used to describe water transport on, e.g., spider silks. ${ }^{36}$ and can be used to align other high aspect ratio materials. ${ }^{37}$ While the horizontal alignment of PNTs observed in this study was not only at the mask edges as previously reported ${ }^{\mathbf{1 6}}$ and instead covered most of the area of the mask openings, the results presented here validate the mechanism of alignment proposed in ref. 16. No further improvement in the alignment was achieved by etching the $\mathrm{Si}$ substrate to remove the native oxide prior to surface patterning. To rule out that the alignment resulted from a topographical feature, if present, at the mask edge arising due to the oxide growth, a Si substrate was exposed to UV/ozone first with the mask for 20 minutes and then for an additional 20 minutes without the mask. Thus, this sample had a similar topography as a sample exposed once using a mask and uniform wettability, however, no alignment was observed (Fig. S1; $\dagger$ FWHM of $\left.69 \pm 3^{\circ}\right)$.

Having identified the driving force for alignment and the optimal UV/ozone exposure time (20 minutes; the exposure time used for all subsequent experiments), the influence of FF concentration and mask opening size was investigated. The SEM images presented in Fig. 2 show that PNT alignment depends on both FF concentration and the opening size of the mask. It was found that using 4 and $2 \mathrm{mg} \mathrm{ml}^{-1} \mathrm{FF}$ with a $0.9 \mathrm{~cm}$

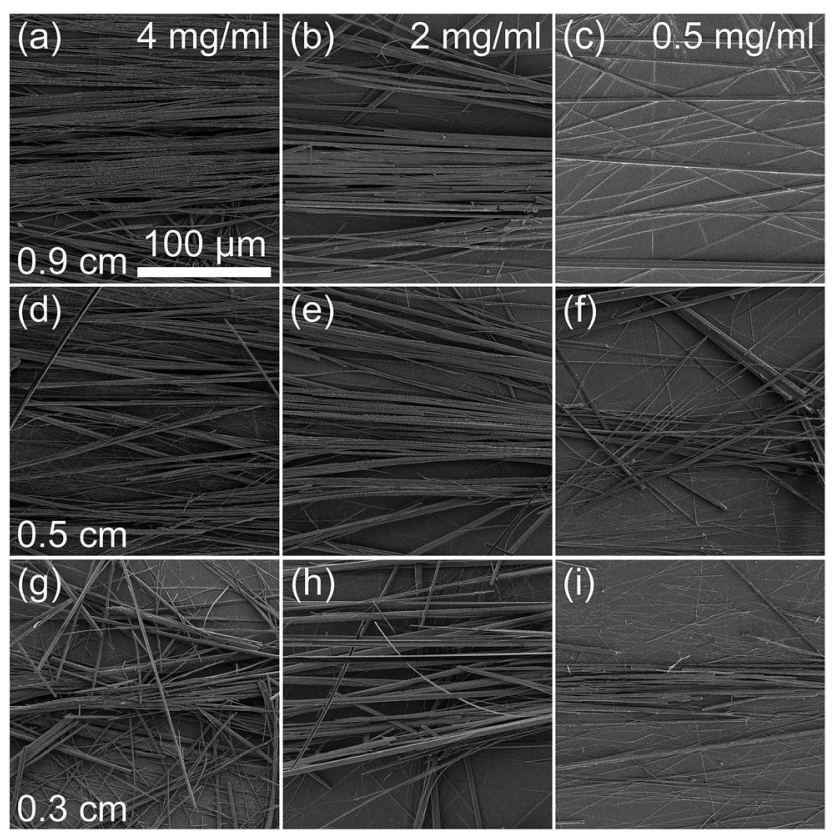

Fig. 2 SEM images of aligned PNTs formed using 4, 2, and $0.5 \mathrm{mg} \mathrm{ml}^{1}$ FF solutions and (a c) $0.9 \mathrm{~cm}$, (d f) $0.5 \mathrm{~cm}$, and (g, e and h) $0.3 \mathrm{~cm}$ mask openings, respectively. 
opening can yield aligned PNTs with a high degree of alignment (14 $\pm 1^{\circ}$ and $14 \pm 2^{\circ}$, respectively), as determined from optical micrographs (Fig. S2 $\dagger$ ) and illustrated using SEM images (Fig. 2(a) and (b)). However, for $0.5 \mathrm{mg} \mathrm{ml}^{-1} \mathrm{FF}$, the $0.9 \mathrm{~cm}$ opening results in relatively poor alignment $\left(31 \pm 5^{\circ}\right.$, Fig. $\left.2(\mathrm{c})\right)$. Changing the value of the opening size from $0.9 \mathrm{~cm}$ to $0.5 \mathrm{~cm}$ also results in aligned PNTs with different degrees of alignment depending on the FF concentration. The FWHM was $19 \pm 4^{\circ}, 17$ $\pm 3^{\circ}$, and $26 \pm 2^{\circ}$, for 4 (Fig. 2(d)), 2 (Fig. 2(e)), and $0.5 \mathrm{mg} \mathrm{ml}^{-1}$ FF (Fig. 2(f)), respectively. Upon reducing the opening size to 0.3 $\mathrm{cm}$, the degree of alignment was determined to be $28 \pm 4^{\circ}, 21 \pm$ $3^{\circ}$, and $20 \pm 2^{\circ}$, for 4 (Fig. $2(\mathrm{~g})$ ), 2 (Fig. $2(\mathrm{~h})$ ), and $0.5 \mathrm{mg} \mathrm{ml}^{-1} \mathrm{FF}$ (Fig. 2(i)), respectively. These results are summarised in Table 2.

In general, it can be concluded that for high concentrations ( 4 and $2 \mathrm{mg} \mathrm{ml}^{-1}$ ), alignment is best for larger $(0.9$ and $0.5 \mathrm{~cm})$ opening sizes, whereas for a low concentration $\left(0.5 \mathrm{mg} \mathrm{ml}^{-1}\right)$, the alignment is best for the smallest $(0.3 \mathrm{~cm})$ opening size for fixed volume droplets. To investigate this effect further, the average diameter of the PNTs was determined from the SEM images (Fig. 2). The diameter was found to increase with increasing concentration and opening size from $0.23 \pm 0.08$ for an opening size of $0.3 \mathrm{~cm}$ and a concentration of $0.5 \mathrm{mg} \mathrm{ml}^{-1}$ to $0.74 \pm 0.08 \mu \mathrm{m}$ for an opening size of $0.9 \mathrm{~cm}$ and a concentration of $4.0 \mathrm{mg} \mathrm{ml}^{-1}$ (Table 2). Thus, the higher the concentration, the larger are the structures that form. As room temperature FF solutions are opaque, dependent on concentration, supramolecular structures have already formed in solution. ${ }^{13}$ The results suggest that the requirements for aligning PNTs depend on their size (i.e., concentration) and the area of the mask opening.

It has previously been reported that the size of the supramolecular FF structures can be controlled by heating the FF solution..$^{13}$ The structures were reported to reversibly disassemble upon heating at $90^{\circ} \mathrm{C}$ for 5 minutes, resulting in a transparent $\mathrm{FF}$ solution, and reassemble upon cooling to room temperature, when the solution became opaque. ${ }^{13}$ To investigate the influence of using heated FF solution, having disassembled PNTs, on the self-assembly and alignment of PNTs on wettability-patterned Si substrates, the alignment experiment was repeated using heated $2 \mathrm{mg} \mathrm{ml}^{-1} \mathrm{FF}$ solution.

Table 2 The influence of FF concentration and mask opening size on the degree of alignment determined from optical micrographs (not shown) and the PNT diameter. See Fig. S2 for optical images

\begin{tabular}{llll}
\hline $\begin{array}{l}\text { Concentration } \\
\left(\mathrm{mg} \mathrm{ml}^{1}\right)\end{array}$ & $\begin{array}{l}\text { Opening } \\
\text { size }(\mathrm{cm})\end{array}$ & $\begin{array}{l}\text { FWHM } \\
\left({ }^{\circ}\right)\end{array}$ & $\begin{array}{l}\text { Diameter } \\
(\mu \mathrm{m})\end{array}$ \\
\hline 4.0 & 0.9 & $14 \pm 1$ & $0.74 \pm 0.08$ \\
4.0 & 0.5 & $19 \pm 4$ & $0.61 \pm 0.08$ \\
4.0 & 0.3 & $28 \pm 4$ & $0.57 \pm 0.08$ \\
2.0 & 0.9 & $14 \pm 2$ & $0.59 \pm 0.08$ \\
2.0 & 0.5 & $17 \pm 1$ & $0.40 \pm 0.08$ \\
2.0 & 0.3 & $21 \pm 3$ & $0.39 \pm 0.08$ \\
0.5 & 0.9 & $31 \pm 5$ & $0.31 \pm 0.08$ \\
0.5 & 0.5 & $26 \pm 3$ & $0.29 \pm 0.08$ \\
0.5 & 0.3 & $20 \pm 2$ & $0.23 \pm 0.08$
\end{tabular}
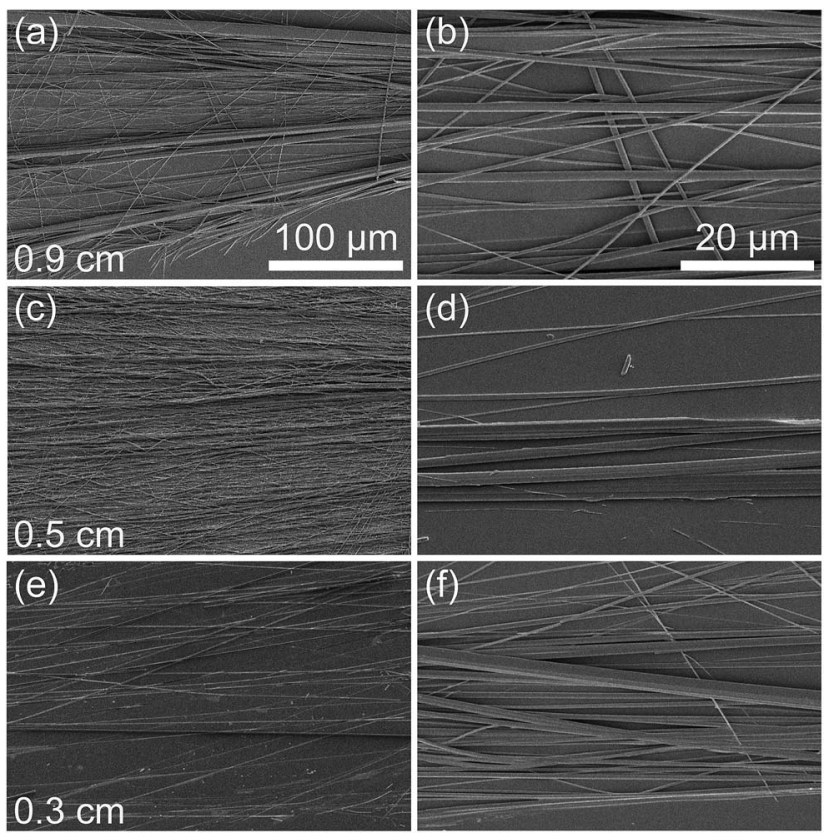

Fig. 3 SEM images of aligned heated PNTs ( $2 \mathrm{mg} \mathrm{ml}^{1} \mathrm{FF}$ ) prepared using ( $a$ and b) $0.9 \mathrm{~cm}$, ( $c$ and d) $0.5 \mathrm{~cm}$, and (e and f) $0.3 \mathrm{~cm}$ mask openings.

From the SEM images (Fig. 3), the average diameter of the resulting PNTs was determined to be $0.10 \pm 0.05 \mu \mathrm{m}$ for an opening size of $0.5 \mathrm{~cm}$, a reduction in size consistent with the findings reported in ref. 13. As the diameter of the PNTs is reduced even compared to the unheated $0.5 \mathrm{mg} \mathrm{ml}^{-1}$ solution, one might expect improved alignment for the $0.3 \mathrm{~cm}$ opening for a fixed volume size. From the optical micrographs (Fig. S3 $\dagger$ ), the FWHM was determined to be $21 \pm 2^{\circ}, 17 \pm 1^{\circ}$, and $15 \pm 2^{\circ}$ for $0.9,0.5$, and $0.3 \mathrm{~cm}$ opening sizes, respectively. The trend is opposite to that reported for the unheated $2 \mathrm{mg} \mathrm{ml}^{-1} \mathrm{FF}$ solution (Table 2) and matches that of the unheated $0.5 \mathrm{mg} \mathrm{ml}^{-1}$ solution. In general, as the PNT diameter increases, so too should the mask opening area in order to achieve optimal alignment. PNT length may be a critical size factor as well, but was not studied here. Comparison of Fig. 2 and 3 suggests that heating the FF solution also appears to provide a route to tailor the density of the PNTs, which is qualitatively reduced on PNT surfaces prepared using the heated FF solution.

In order to investigate the suitability of the aligned PNTs for sensing applications, a prototype device was fabricated by aligning PNTs decorated with Ag NPs prepared by heating the 2 $\mathrm{mg} \mathrm{ml} \mathrm{m}^{-1} \mathrm{FF}$ and $\mathrm{Ag} \mathrm{NP}$ solution and using an opening size of 0.5 $\mathrm{cm}$ (Fig. 4). Equivalent alignment (Fig. S4; $\dagger$ FWHM $=17 \pm 1^{\circ}$ ) was achieved of PNTs with and without Ag NPs. The average diameter of the resulting PNTs remained unchanged $(0.10 \pm$ $0.06 \mu \mathrm{m})$.

Raman spectroscopy was then used to characterise the prototype device. The Raman intensity for aligned PNTs $(\sim 30 \times$ $10^{3}$ counts) was stronger than that for randomly oriented PNTs $\left(\sim 24 \times 10^{3}\right.$ counts), as shown in Fig. 5(a). The spectra possess features in agreement with those reported in the literature, e.g., 

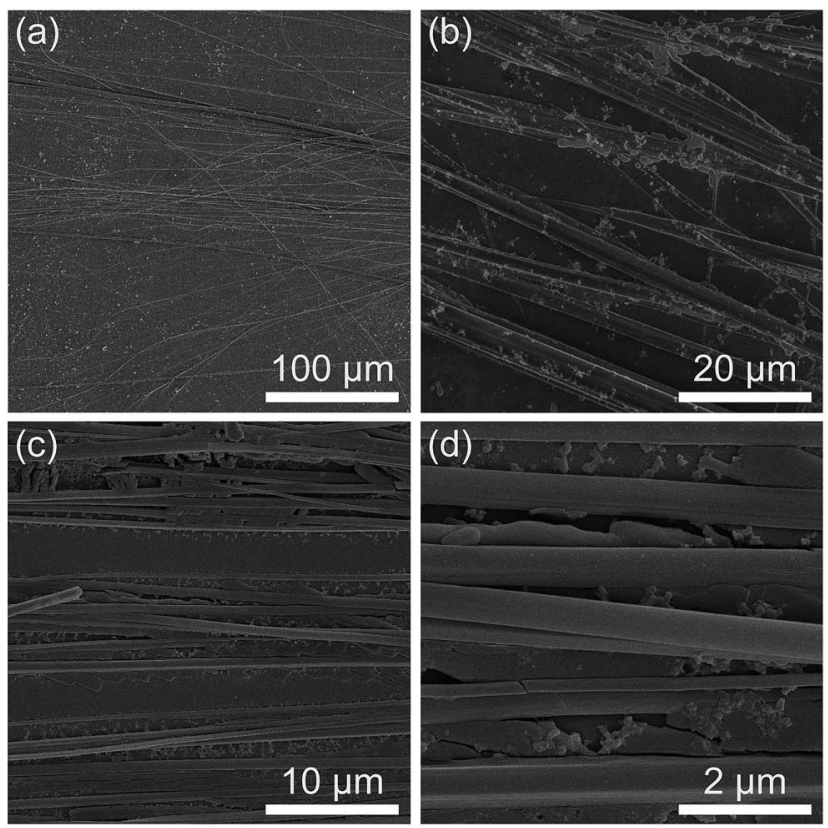

Fig. 4 ( $a$ and b) SEM images of PNTs coated with Ag NPs. (c and d) SEM images of aligned Ag NP-coated PNTs after adding TMPyP.

(a)
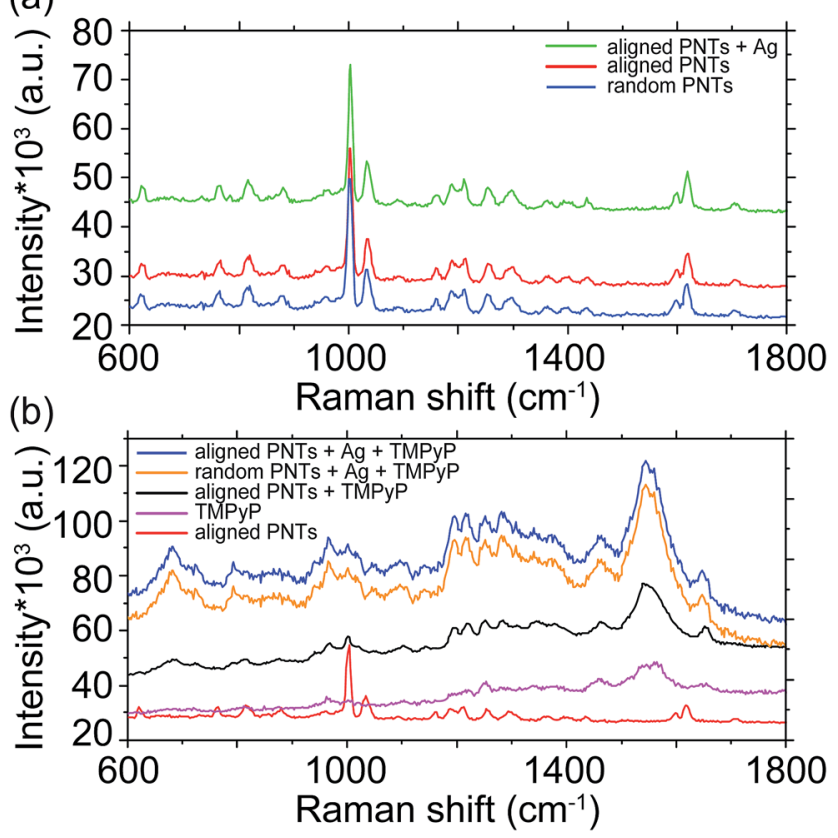

Fig. 5 (a) Raman spectra of aligned PNTs with (green) and without (red) Ag NPs and randomly oriented (blue) PNTs without Ag NPs. (b) Raman spectra of aligned PNTs (red), TMPyP (pink), aligned PNTs + TMPyP (black), and aligned PNTs + Ag + TMPyP (purple).

an aromatic ring breathing mode at $1002 \mathrm{~cm}^{-1}$ and a phenyl vibrational band at $1603 \mathrm{~cm}^{-1} \cdot{ }^{38}$ It is likely that the stronger intensity for the aligned versus randomly oriented PNTs results from the higher density of PNTs that form as a result of the hydrophobic confinement of the FF solution (see Fig. 1(a) and (c)). The Raman spectrum for aligned PNTs formed with Ag NPs revealed significant enhancement in Raman intensity compared to PNTs without Ag (Fig. 5(a)). The presence of Ag NPs does not measurably alter the Raman band position or relative intensities for PNTs, suggesting that the Ag NPs are predominantly on the surface of the PNTs, as visible in the SEM images (Fig. 4(a) and (b)).

Raman spectra were also recorded after applying an analyte to the aligned PNTs coated with Ag NPs. It has been reported previously that dried PNTs can dissolve in solution. ${ }^{39}$ Similarly, when a drop of analyte solution was placed on aligned PNTs without Ag NPs, the PNTs were no longer aligned (Fig. S5; $\dagger$ FWHM of $67 \pm 2^{\circ}$ ), suggesting they disassembled and reassembled. However, the presence of the Ag NPs appeared to provide stability to the aligned PNTs, since the diameter $(0.10 \pm$ $0.06 \mu \mathrm{m}$ ) as determined by SEM (Fig. 4(c) and (d)) and alignment (Fig. S4; $\dagger$ FWHM of $17 \pm 1^{\circ}$ before and after application of the analyte) remained unchanged. The stability of dried PNTs following exposure to solution has been shown previously to improve with the incorporation of nanomaterials. ${ }^{40}$ The Raman spectrum of the analyte molecule (TMPyP) is shown in Fig. 5(b). The spectra for PNT + TMPyP with and without Ag NPs showed similar spectral features (Fig. 5(b)), however, the spectrum with Ag NPs showed a higher Raman spectral intensity $\left(\sim 44 \times 10^{3}\right.$ counts), indicating plasmonic enhancement of the Raman signal. The spectra for PNT + TMPyP with and without Ag NPs both show bands in agreement with TMPyP Raman bands reported in the literature, ${ }^{\mathbf{4 1 , 4 2}}$ e.g., $\mathrm{A}_{1 \mathrm{~g}}$ modes at 1249 (C-pyrrole bending), 1451, 1557 (C-C stretching), and 1639 (pyrrole bending) $\mathrm{cm}^{-1}$.

While the demonstration of plasmonic enhancement both of the PNT and the analyte is a promising result highlighting the potential of aligned PNTs for sensing applications, further improvements may be achieved by (i) exploring other methods to incorporate and control the density and location of nanomaterials within or alongside the aligned PNTs, ${ }^{43} 46$ (ii) optimising the stability of PNTs when exposed to solution, and (iii) tailoring the density and diameter of the aligned PNTs.

\section{Conclusions}

Horizontal alignment of PNTs was successfully achieved using UV/ozone exposure through a mask designed to create wettability gradients. The degree of alignment was found to improve with increasing exposure time, coincident with an increasing chemical force resulting from the difference in wettability between regions. Optimal alignment was found to depend on the interplay between the concentration- and temperaturedependent diameter of the PNTs and the mask opening size (hydrophilic area); larger diameter PNTs had better alignment when the widest openings studied were used. Alignment of PNTs decorated with Ag NPs was also demonstrated, which served as a prototype sensing device of an analyte (TMPyP) using Raman spectroscopy. The Ag NPs stabilised the PNTs during the application of the analyte and plasmonically enhanced the Raman signal. The tunable alignment of PNTs and proof of principle demonstration of SERS-based sensing 
demonstrated here may enable the further development of PNTs in nanobiotechnology applications, including as a template for organising nanomaterials.

\section{Acknowledgements}

This research was funded by the Ministry of Higher Education of Saudi Arabia under the King Abdullah Scholarship Program (ref. no. IR10161) and the European Commission within FP7 Marie Curie Initial Training Network "Nanomotion" (grant agreement no. 290158). The authors acknowledge Ian Reid for assistance with SEM, Peng Li and Gil Lee for assistance with etching Si substrates and contact angle measurements, and Dimitri Scholz of the UCD Conway Imaging Core Facility and Bartlomiej Lukasz for assistance with optical microscopy. ALK acknowledges support from the Russian Scientific Foundation (grant no. 14-12-00812) and the CICECO - Aveiro Institute of Materials (FCT UID/CTM/50011/2013), financed by national funds through the FCT/MEC and when applicable co-financed by FEDER under the PT2020 Partnership Agreement. JHR acknowledges support from Science Foundation Ireland (grant 12/IP/1556).

\section{Notes and references}

1 M. Reches and E. Gazit, Nat. Nanotechnol., 2006, 1, 195-200.

2 K. B. Andersen, $P h D$ Thesis, Technical University of Denmark, 2013.

3 A. Handelman, A. Natan and G. Rosenman, J. Pept. Sci., 2014, 20, 487-493.

4 R. Orbach, L. Adler-Abramovich, S. Zigerson, I. MironiHarpaz, D. Seliktar and E. Gazit, Biomacromolecules, 2009, 10, 2646-2651.

5 A. Lakshmanan, S. Zhang and C. A. E. Hauser, Trends Biotechnol., 2012, 30, 155-165.

6 A. Kholkin, N. Amdursky, I. Bdikin, E. Gazit and G. Rosenman, ACS Nano, 2010, 4, 610-614.

7 K. Ryan, J. Beirne, G. Redmond, J. I. Kilpatrick, J. Guyonnet, N.-V. Buchete, A. L. Kholkin and B. J. Rodriguez, ACS Appl. Mater. Interfaces, 2015, 7, 12702-12707.

8 L. Adler-Abramovich, M. Reches, V. L. Sedman, S. Allen, S. J. B. Tendler and E. Gazit, Langmuir, 2006, 22, 1313-1320.

9 L. Adler-Abramovich, D. Aronov, P. Beker, M. Yevnin, S. Stempler, L. Buzhansky, G. Rosenman and E. Gazit, Nat. Nanotechnol., 2009, 4, 849-854.

10 X. Chen, J. Li, G. Zhang and Y. Shi, Adv. Mater., 2011, 23, 3965-3969.

11 A. Nuraeva, S. Vasilev, D. Vasileva, P. Zelenovskiy, D. Chezganov, A. Esin, S. Kopyl, K. Romanyuk, V. Y. Shur and A. L. Kholkin, Cryst. Growth Des., 2016, acs.cgd.5b01604.

12 J. Kim, T. H. Han, Y.-I. Kim, J. S. Park, J. Choi, D. G. Churchill, S. O. Kim and H. Ihee, Adv. Mater., 2010, 22, 583-587.

13 R. Huang, Y. Wang, W. Qi, R. Su and Z. He, Nanoscale Res. Lett., 2014, 9, 653.
14 A. Heredia, I. Bdikin, S. Kopyl, E. Mishina, S. Semin, A. Sigov, K. German, V. Bystrov, J. Gracio and A. L. Kholkin, J. Phys. D: Appl. Phys., 2010, 43, 462001.

15 N. Amdursky, P. Beker, I. Koren, B. Bank-Srour, E. Mishina, S. Semin, T. Rasing, Y. Rosenberg, Z. Barkay, E. Gazit and G. Rosenman, Biomacromolecules, 2011, 12, 1349-1354.

16 L. Adler-Abramovich, D. Aronov, E. Gazit and G. Rosenman, J. Nanosci. Nanotechnol., 2009, 9, 1701-1708.

17 B. Lekprasert, V. Korolkov, A. Falamas, V. Chis, C. J. Roberts, S. J. B. Tendler and I. Notingher, Biomacromolecules, 2012, 13, 2181-2187.

18 C. M. Kelly, T. Northey, K. Ryan, B. R. Brooks, A. L. Kholkin, B. J. Rodriguez and N.-V. Buchete, Biophys. Chem., 2015, 196, 16-24.

19 J. Castillo, S. Tanzi, M. Dimaki and W. Svendsen, Electrophoresis, 2008, 29, 5026-5032.

20 G. Rosenman, P. Beker, I. Koren, M. Yevnin, B. Bank-Srour, E. Mishina and S. Semin, J. Pept. Sci., 2011, 17, 75-87.

21 J. Castillo-León, K. Andersen and W. Svendsen, in Biomaterials Science and Engineering, ed. R. Pignatello, InTech, Rijeka, Croatia, 2011, pp. 115-138.

22 L. Adler-Abramovich and E. Gazit, J. Pept. Sci., 2008, 14, 217223.

23 J. Ryu and C. B. Park, Adv. Mater., 2008, 20, 3754-3758.

24 N. Hendler, N. Sidelman, M. Reches, E. Gazit, Y. Rosenberg and S. Richter, Adv. Mater., 2007, 19, 1485-1488.

25 K. B. Andersen, J. Castillo-León, T. Bakmand and W. E. Svendsen, Jpn. J. Appl. Phys., 2012, 51, 06FF13.

26 B. Lekprasert, V. Korolkov, A. Falamas, V. Chis, C. J. Roberts, S. J. B. Tendler and I. Notingher, Biomacromolecules, 2012, 13, 2181-2187.

27 R. Franco, J. L. Jacobsen, H. Wang, Z. Wang, K. István, N. E. Schore, Y. Song, C. J. Medforth and J. A. Shelnutt, Phys. Chem. Chem. Phys., 2010, 12, 4072-4077.

28 A. Bhattacharya, J. Cheng, S. Bhosale, A. Aphale, P. K. Patra and I. Mukerji, Spectroscopy, 2012, 27, 2-8.

29 F. Sinjab, G. Bondakov and I. Notingher, Appl. Phys. Lett., 2014, 104, 251905.

30 W. Xie and S. Schlücker, Rep. Prog. Phys., 2014, 77, 116502.

31 M. Reches and E. Gazit, Science, 2003, 300, 625-627.

32 R. Djalali, Y. F. Chen and H. Matsui, J. Am. Chem. Soc., 2003, 125, 5873-5879.

33 O. Carny, D. E. Shalev and E. Gazit, Nano Lett., 2006, 6, 15941597.

34 S. Damm, N. Craig Carville, M. Manzo, K. Gallo, S. G. Lopez, T. E. Keyes, R. J. Forster, B. J. Rodriguez and J. H. Rice, Appl. Phys. Lett., 2013, 103, 083105.

35 S. Damm, N. C. Carville, B. J. Rodriguez, M. Manzo, K. Gallo and J. H. Rice, J. Phys. Chem. C, 2012, 116, 26543-26550.

36 J. Ju, Y. Zheng and L. Jiang, Acc. Chem. Res., 2014, 47, 23422352.

37 S. Liu, J. B.-H. Tok, J. Locklin and Z. Bao, Small, 2006, 2, 1448-1453.

38 B. Lekprasert, V. Sedman, C. J. Roberts, S. J. B. Tedler and I. Notingher, Opt. Lett., 2010, 35, 4193-4195.

39 K. B. Andersen, J. Castillo-Leon, M. Hedström and W. E. Svendsen, Nanoscale, 2011, 3, 994-998. 
40 K. Ryan, PhD Thesis, University College Dublin, 2015.

41 N. Blom, J. Odo, K. Nakamoto and D. P. Strommen, J. Phys. Chem., 1986, 90, 2847-2852.

42 K. Šišková, O. Bečička, V. Mašek, K. Šafářová and R. Zbořil, J. Raman Spectrosc., 2012, 43, 689-691.

43 H. Matsui and R. MacCuspie, Nano Lett., 2001, 1, 671-675.

44 J. Ryu and C. B. Park, Angew. Chem., 2009, 48, 4820-4823.
45 C. Reiriz, R. J. Brea, R. Arranz, J. L. Carrascosa, A. Garibotti,

B. Manning, J. M. Valpuesta, R. Eritja, L. Castedo and J. R. Granja, J. Am. Chem. Soc., 2009, 131, 11335-11337.

$46 \mathrm{~J}$. Montenegro, C. Vázquez-Vázquez, A. Kalinin, K. E. Geckeler and J. R. Granja, J. Am. Chem. Soc., 2014, 136, 2484-2491. 